\title{
Interannual Variability of Boreal Summer Rainfall in the Equatorial Atlantic
}

\author{
Guojun Gu and Robert F. Adler
}

\section{Popular Summary}

Severe weather events frequently appear in the tropical Atlantic basin during boreal summer [June-July-August (JJA)], in particular the Atlantic hurricane activity. The yearto-year changes of these phenomena are evident and directly related to convection and rainfall changes in the basin and the strength of the ITCZ. Local sea surface temperature (SST) variabilities are known to be important factors. Probably due to a much smaller size of the Atlantic than the Pacific, convection and rainfall in the tropical Atlantic are also heavily affected by the variations in the tropical Pacific, specifically the Pacific ENSO. Thus, the two major purposes of this study are to (1) document the boreal summer year-to-year rainfall changes in the tropical Atlantic, and (2) assess and further try to discern the impacts from local SST variations and the Pacific ENSO, by means of a 28year (1979-2006) monthly precipitation dataset from the Global Precipitation Climatology Project (GPCP).

The changes in the ITCZ strength and the basin-mean rainfall during JJA are comparable to the changes during boreal spring [March-April-May (MAM)] when the most intense rainfall variability is usually observed. However, the ITCZ's preferred latitudes do not vary much during $\mathrm{JJA}$, in contrasting to its intense year-to-year fluctuations during MAM.

Local SST variations include two types: One is along the equatorial region (usually called the Atlantic Niño events), another in the tropical north Atlantic (TNA) covering the tropical storm development region. They can modulate the tropical Atlantic climate during both seasons. During MAM, both of them contribute to the formation of an evident interhemispheric SST gradient, which shifts the latitudinal position of the ITCZ particularly in the western basin. This anomalous shifting of the ITCZ is the major causesof droughts/floods over South America. During JJA however their impact is primarily on the ITCZ strength and basin-mean rainfall which may directly be associated with the evolution of tropical waves and storms.

The Pacific ENSO has a strong effect on the tropical Atlantic during both seasons too. Particularly, the Pacific ENSO may directly impact the rainfall changes during JJA through an anomalous Walker cell, that is, a large-scale tropical atmospheric zonal circulation, in addition to its effect on the tropical Atlantic SST. 


\section{Interannual Variability of Boreal Summer Rainfall in the Equatorial Atlantic}

Guojun Gu $^{\# @^{*}}$, and Robert F. Adler ${ }^{@}$

\# Goddard Earth Sciences and Technology Center, University of Maryland Baltimore County, Baltimore, MD

${ }^{\circledR}$ Laboratory for Atmospheres, NASA Goddard Space Flight Center, Greenbelt, MD

International Journal of Climatology

(August 2007)

* Corresponding author address: Dr. Guojun Gu, Code 613.1, NASA/GSFC, Greenbelt, MD 20771.ggu@agnes.gsfc.nasa.gov 


\begin{abstract}
Tropical Atlantic rainfall patterns and variation during boreal summer [June-July-August (JJA)] are quantified by means of a 28-year (1979-2006) monthly precipitation dataset from the Global Precipitation Climatology Project (GPCP). Rainfall variability during boreal spring [March-April-May (MAM)] is also examined for comparison in that the most intense interannual variability is usually observed during this season. Comparable variabilities in the ITCZ strength and the basin-mean rainfall are found during both seasons. Interannual variations in the ITCZ's latitudinal location during JJA however are generally negligible, in contrasting to intense yearto-year fluctuations during MAM.
\end{abstract}

Sea surface temperature (SST) oscillations along the equatorial region (usually called the Atlantic Niño events) and in the tropical north Atlantic (TNA) are shown to be the two major local factors modulating the tropical Atlantic climate during both seasons. During MAM, both SST modes tend to contribute to the formation of an evident interhemispheric SST gradient, thus inducing anomalous shifting of the ITCZ and then forcing a dipolar structure of rainfall anomalies across the equator primarily in the western basin. During JJA the impacts however are primarily on the ITCZ strength likely due to negligible changes in the ITCZ latitudinal location. The Atlantic Niño reaches its peak in JJA, while much weaker SST anomalies appear north of the equator in JJA than in MAM, showing decaying of the interhemispheric SST mode.

SST anomalies in the tropical central-eastern Pacific (the El Niño events) have a strong impact on tropical Atlantic including both the tropical north Atlantic and the equatorial-southern Atlantic. However, anomalous warming in the tropical north Atlantic following positive SST anomalies in the tropical Pacific disappears during JJA because of seasonal changes in the largescale circulation cutting off the ENSO influence passing through the mid-latitudes. Hence the 
anomalies associated with the tropical Pacific during JJA are forced through an anomalous Walker circulation primarily working on the western basin, and likely a lagged oceanic response in the equatorial region. 


\section{Introduction}

Atlantic climate variability has been shown and extensively explored (e.g., Lamb 1978a, b; Carton and Huang 1994; Nobre and Shukla 1996; Sutton et al. 2000). The Atlantic Niño and an interhemispheric sea surface temperature (SST) gradient mode have been discovered to be the major local forcings (e.g., Zebiak 1993; Nobre and Shukla 1996), in addition to the two other remote large-scale modulators: the El Niño-Southern Oscillation (ENSO) and the North Atlantic Oscillation (NAO) (e.g., Curtis and Hastenrath 1995; Chiang et al. 2002; Wang 2002). Anomalous rainfall, SST, and wind fields in the tropical ocean basin are also closely related to climate oscillations over two neighboring continents, i.e., South America and West Africa (e.g., Lamb 1978a, b; Hastenrath and Greischar 1993; Nobre and Shukla 1996; Wagner 1996). The most intense interannual variability usually occurs during boreal spring [March-April-May (MAM)] as the ITCZ moves close to the equator, specifically in the western basin and over the northeastern portion of South America (e.g., Hastenrath and Greischar 1993; Nobre and Shukla 1996). Thus, most of previous studies were concentrated on this season (e.g., Chiang et al. 2002; Gu and Adler 2006).

As illustrated in Gu and Adler (2006), interannual variability in the tropical Atlantic is also evident during boreal summer [June-July-August (JJA)]. The Atlantic Niño reaches its peak during this season, and the impact of the interhemispheric SST gradient mode and ENSO may still be felt in the equatorial region (e.g., Sutton et al. 2000; Chiang et al. 2002). Particularly, evident year-to-year variations exist in various distinct severe weather phenomena such as African easterly waves (AEW) and associated convection, and Atlantic hurricane activity (e.g., Thorncroft and Rowell 1998; Landsea et al. 1999). These usually-raining systems frequently appear during boreal summer and fall, and move westward near the latitudes of the ITCZ (e.g., 
Chen and Ogura 1982; Gu and Zhang 2001). Hence this study will primarily focus on rainfall variability and associated climate anomalies during boreal summer.

Our purposes are (i) to quantify the rainfall-related variability on the interannual time scale during boreal summer, and then (ii) to further examine the effects of the two local SST modes and ENSO. Gu and Adler (2006) analyzed various simultaneous correlation relations as function of time (month), but did not further examine their spatial structures specifically during boreal summer. Anomalous rainfall, SST and surface wind patterns during MAM will also be reexamined for comparison and for an analysis of time persistence in climate variability, in that the most intense climate fluctuations have been found during this season (e.g., Hastenrath and Greischar 1993; Nobre and Shukla 1996).

Data sets used here are briefly discussed in section 2. Section 3 reports the major results including summer-time rainfall variability and associated various correlation relationships, and their possible physical mechanisms. Spatial structures of local SST-related anomalies and ENSO responses in the tropical Atlantic are further investigated. Summary and conclusions are given in section 4.

\section{Brief Description of Data}

A 28-year (1979-2006) monthly precipitation dataset from the Global Precipitation Climatology Project (GPCP) is used to quantify rainfall anomalies within the tropical Atlantic basin. On a global $2.5^{\circ} \times 2.5^{\circ}$ grid, the data is combined from various sources (Adler et al. 2003):

the infrared (IR) rainfall estimates from geostationary and polar-orbiting satellites, the microwave estimates from Special Sensor Microwave/Imager (SSM/I), and surface rain gauges from the Global Precipitation Climatological Centre (GPCC). 
The SST anomalies and related primary oscillation modes ${ }^{1}$ in the both tropical Atlantic and Pacific are computed using the National Centers for Environmental Prediction (NCEP) SST satellite product (Reynolds et al. 2002). This product is archived on $1^{\circ} \times 1^{\circ}$ grids and lasts from January 1982 to the present. Thus, to keep consistency between the various datasets used here, we focused on the time period of January 1982-December 2006.

In addition, monthly wind components from the NCEP/DOE AMIP-II reanalysis project (Kanamitsu et al. 2002) are used to provide a description of large-scale wind anomalies.

\section{Results}

\subsection{Rainfall and variability during boreal spring and summer}

Detailed seasonal variations in the tropical Atlantic have been documented in past studies (e.g., Mitchell and Wallace 1992; Biasutti et al. 2004; Gu and Adler 2004). Here we only give a brief summary of seasonal changes in SST and rainfall, and their corresponding variances during MAM and JJA (Fig. 1). Seasonal oceanic rainfall generally stays over warm SST $\left(\geq 27^{\circ} \mathrm{C}\right)$, featuring the climatological state of the ITCZ. The maritime rainfall band or the ITCZ is closely connected to the rainfall zones over the two neighboring continents. During MAM, the most intense rainfall zone is located over the coastal region of the northeastern South America; simultaneously the oceanic rainfall band/ITCZ approaches the equator, following the warmest SST in the equatorial region due to the relaxation of trade winds, particularly in the eastern basin. During JJA, an equatorial cold tongue-ITCZ complex forms with the maritime ITCZ becoming the strongest and moving to the north, while another two rainfall zones can simultaneously be

${ }^{1}$ All anomalies, rainfall and SST indices are de-trended here as we primarily focus on interannual variability. 
seen over northern South America and West Africa, respectively.

During MAM the most intense rainfall variability occurs in the western equatorial region, especially along the coastline. In contrast, the maximum SST variances tend to be in the eastern basin, and are concentrated in three major areas: tropical north Atlantic $\left(\sim 5^{\circ} \mathrm{N}-25^{\circ} \mathrm{N}\right)$, the equatorial region, and tropical south Atlantic $\left(\sim 10^{\circ} \mathrm{S}-25^{\circ} \mathrm{S}\right)$. Furthermore, the most intense SST variability tends to be away from the equator, with thus a much weaker SST variability along the equator. During JJA, rainfall variances are mostly found to be over the open ocean along the mean latitudes of the ITCZ. Major SST variability occurs in the equatorial region, likely corresponding to the frequent appearance of the Atlantic Niño events (e.g., Zebiak 1993; Carton and Huang 1994). Interestingly, rainfall variances within the interior of two continents, particularly over West Africa, are much smaller compared with over ocean and coastal regions.

To further quantitatively investigate rainfall variability, two indices are defined to represent the strength $\left(\mathrm{P}_{\mathrm{ITCZ}}\right)$ and latitude (Lat ITCZ) variations of the marine ITCZ, respectively, with another one denoting the rainfall variability within the entire tropical Atlantic basin $\left(\mathrm{P}_{\mathrm{dm}}\right)$. The ITCZ location and strength here are quantified by the latitudes of maximum monthly rainfall averaged between $15^{\circ} \mathrm{W}-35^{\circ} \mathrm{W}$, and rainfall values estimated by averaging this maximum value with the values at two neighboring latitudes, respectively. The ITCZ latitudes are further modified through a 1-2-1 interpolation by the two neighboring latitudes based on their corresponding rainfall magnitudes. The basin-mean rainfall is computed over a domain of $15^{\circ} \mathrm{S}-$ $22.5^{\circ} \mathrm{N}, 15^{\circ} \mathrm{W}-35^{\circ} \mathrm{W} . \mathrm{P}_{\mathrm{ITCZ}}$, Lat ${ }_{\mathrm{ITCZ}}$, and $\mathrm{P}_{\mathrm{dm}}$ are finally determined by subtracting their corresponding mean seasonal cycles during this 28 -year period.

Time series of the three indices during MAM and JJA are depicted in Fig. 2. Rainfall changes during these two seasons are comparable whether examined by using either $\mathrm{P}_{\mathrm{ITCZ}}$ or $\mathrm{P}_{\mathrm{dm}}$. 
However, the ITCZ does not change its latitudinal positions much during JJA, in contrast to evident fluctuations during MAM. Thus the major changes during the boreal summer are mostly related to the variability in the ITCZ strength and/or the basin-total rainfall. This probably implies a lack of forcing mechanism on the ITCZ preferred latitudinal positions during JJA. Past studies suggested that the Atlantic interhemispheric SST mode, though a dominant factor of the ITCZ position during MAM, becomes secondary during boreal summer (e.g., Sutton et al. 2000; Gu and Adler 2006). Hence the variability in the ITCZ strength and the basin-mean rainfall during JJA will be focused on hereafter.

\subsection{Rainfall variability associated SST anomalies}

Simultaneous correlation maps between SST anomalies and $\mathrm{P}_{\mathrm{ITCZ}}$ are estimated during the two seasons (Fig. 3). Similar patterns can be obtained between SST anomalies and $\mathrm{P}_{\mathrm{dm}}$ because the high correlation between $\mathrm{P}_{\mathrm{ITCZ}}$ and $\mathrm{P}_{\mathrm{dm}}$ (not shown). Global SST anomalies are estimated by simply subtracting the 25 -year mean seasonal cycle from monthly SST at each grid point. The difference between these two seasons is evident. During MAM, the ITCZ strength is strongly correlated to SST anomalies in both the equatorial Pacific and Atlantic. Significant, negative correlations can be seen in the central-eastern equatorial Pacific, indicating the remote modulation of the Pacific El Niño. Within the tropical Atlantic basin, $\mathrm{P}_{\mathrm{ITCZ}}$ tends to be correlated to SST anomalies along the equator and south of the equator (Fig. 3a). This confirms that the interhemispheric SST mode may strongly impact the ITCZ locations, but have a minor influence on the ITCZ strength and the total rainfall in the basin (e.g., Nobre and Shukla 1996; Gu and Adler 2006).

During JJA, the remote impact from the Pacific becomes weaker and the major high- 
correlation area along the equator moves to the west (Fig. 3b). Within the tropical Atlantic, significant, positive correlations roughly extend to the entire basin from $20^{\circ} \mathrm{S}$ to $20^{\circ} \mathrm{N}$. It is interesting to note that the same sign correlation is found both north and south of the equator, tending to suggest a coherent, local forcing of rainfall variability during this season.

Also, we can find, during both seasons there are two large areas of high correlation in the tropical western Pacific: One is along the South Pacific Convergence Zone (SPCZ), another is north of $10^{\circ} \mathrm{N}$ tilting from southwest to northeast. These two features are probably associated with the ENSO effect, not directly related to the changes in the tropical Atlantic.

To further explore the relationships between rainfall anomalies in the tropical Atlantic and SST variability, particularly during JJA, three major SST indices are constructed. Here, Nino3:4, the mean SST anomalies within a domain of $5^{\circ} \mathrm{S}-5^{\circ} \mathrm{N}, 120^{\circ} \mathrm{W}-170^{\circ} \mathrm{W}$, is as usual used to denote the interannual variability in tropical Pacific as high correlations between PITCZ $_{\text {and }}$ SST anomalies in this domain are seen during both MAM and JJA (Fig. 3). Similar as in Gu and Adler (2006), the SST anomalies within $3^{\circ} \mathrm{S}-3^{\circ} \mathrm{N}, 0-20^{\circ} \mathrm{W}$ are defined as Atl3 to represent the Atlantic Equatorial Oscillation (e.g., Zebiak 1993; Carton and Huang 1994). SST variability in the tropical north Atlantic is denoted by the SST anomalies averaged over a domain of $5^{\circ} \mathrm{N}$ $25^{\circ} \mathrm{N}, 15^{\circ} \mathrm{W}-55^{\circ} \mathrm{W}$ (TNA). In addition, another index (TNA1) is constructed for comparison by the SST anomalies averaged over a slightly smaller domain, $5^{\circ} \mathrm{N}-20^{\circ} \mathrm{N}, 15^{\circ} \mathrm{W}-55^{\circ} \mathrm{W}$. We are not going to focus on the interhemispheric SST mode here because during boreal summer this mode does not significantly impact the ITCZ (e.g., Gu and Adler 2006), and the evident variability of the ITCZ is in its strength rather than its preferred latitude (Fig. 2). The same procedures are applied to $1000-\mathrm{hPa}$ zonal winds in the western basin $\left(5^{\circ} \mathrm{S}-5^{\circ} \mathrm{N}, 25^{\circ} \mathrm{W}-45^{\circ} \mathrm{W}\right)$ to construct a zonal wind anomaly index ( $\left.\mathrm{U}_{\mathrm{WAt}}\right)$, for examining their connection with the equatorial SST variations 
(e.g., Latif and Grötzner 2000).

As discovered in past studies (e.g., Nobre and Shukla 1996; Czaja 2004), evident seasonal preferences exist in these indices (Fig. 4). ENSO usually peaks during boreal winter (solid line in Fig. 4). The most intense variability in the tropical Atlantic appears during boreal spring and early summer. The maxima of both TNA and TNA1 are in April, about three months later than the strongest ENSO signals (e.g., Curtis and Hastenrath 1995; Nobre and Shukla 1996). Surface zonal wind anomaly in the western equatorial region ( $\left.\mathrm{U}_{\mathrm{WAtl}}\right)$ attains its maximum in May, followed by the most intense equatorial SST oscillation (At13) in June. As suggested in Münnich and Neelin (2005), there seems to be a chain reaction during this time period in the equatorial Atlantic region. It is thus arguable that the tropical western Atlantic (west of $20^{\circ} \mathrm{W}$ ) is a critical region passing and/or inducing climate anomalies in the entire tropical Atlantic basin.

\subsubsection{Contemporaneous correlation}

Simultaneous correlations between SST indices are computed for each month (Fig. 5). The Pacific Niño shows strong impact on the tropical Atlantic. Significant correlations are found between Nino3.4 and TNA during February-April with a peak in March. The negative correlation between Nino3.4 and At13 becomes statistically significant during April-June, showing the impact of the ENSO on the Atlantic equatorial mode (e.g., Delecluse et al. 1994; Latif and Grötzner 2000; Gu and Adler 2006). UWAtl is consistently, negatively correlated with Nino3.4 during February-July except in March when the correlation coefficient is lower than the $5 \%$ confidence level. Interestingly, there are two peak months (April and July) for the correlation, similar as discovered by Münnich and Neelin (2005). High correlations between Atl3 and $U_{\text {WAtl }}$ occur almost year-round with only two exceptions: February and October. These 
relations seem to support the idea that zonal wind anomalies at the surface of the western basin are a critical part of the connection between the equatorial Pacific and the variabilities in the equatorial Atlantic. High correlations during November-February are likely corresponding to the occasional appearance of the equatorial oscillation event during boreal fall and winter (e.g., Wang 2002; Gu and Adler 2006).

The correlations between At13 and SST anomalies north of the equator (TNA and TNA1) become positive and strong during late boreal summer, particularly between Atl3 and TNA1 (above the 5\% confidence level during August-October). As shown in Fig. 4, SST variations north of the equator become weaker during boreal summer. Simultaneously the ITCZ and associated trade wind system moves further to the north. It thus seems possible to feel the impact from the equatorial region in the TNA/TNA1 region during this season for surface wind anomalies-driven transport (e.g., Gill 1982).

\subsubsection{Lag-correlation}

Lag-correlations between various SST indices are estimated to further our understanding of the likely, casual relationships among them (Figs. 6, 7, and 8). The base months for SST indices are chosen according to their respective peak months of variances (Fig. 4). The strongest correlation between At13 in June and Nino3.4 is found when Nino3.4 leads Atl3 by one month

(Fig. 6), further confirming the remote forcing of the Atlantic equatorial mode (e.g., Latif and Grötzner 2000). The 1-3 month leading, significant correlation of $U_{\text {WAtl }}$ with Atl3 in June with a peak at one-month leading indicates that the equatorial oscillation is mostly excited by the zonal wind anomalies in the western basin through oceanic dynamics (e.g., Zebiak 1993; Carton and Huang 1994; Delecluse et al. 1994; Latif and Grötzner 2000). Also, the strong correlation with a 
lag of -1 to 1 months and the persistent simultaneous correlation shown in Fig. 5 may suggest that this equatorial mode, similar to, though much weaker than, the Pacific El Niño, might be a coupled process to a certain extent.

The lag-correlation between $U_{\text {WAtl }}$ in May and Nino3.4 is depicted in Fig. 7. The highest correlation appears as Nino3.4 leads $U_{\text {WAtl }}$ by one-month, and interestingly the persistent significant correlations are seen with time-lags even longer than 6 months. This tends to suggest the high sensitivity of zonal winds in the western basin to the changes in the equatorial Pacific (e.g., Latif and Grötzner 2000).

North of the equator, TNA and TNA1 both peak in April (Fig. 4). Simultaneous correlations between the indices and Nino3.4 at the peak month are much weaker than when Nino3.4 leads them by at least one-month (Fig. 8). It is noticed that the persistent high lagcorrelations are seen with Nino3.4 leading by 1-7 months. Significant correlation between TNA and TNA1 in April and Nino3.4 can actually be found as Nino3.4 leads them up to 10 months (not shown). As for the lag-correlations between Nino3.4 and $U_{\text {WAtl }}$ in May (Fig. 7), these highly persistent lag-correlation-relations further suggest that the impact from the equatorial Pacific on the tropical north Atlantic may go through two ways: the Pacific-North-American (PNA) teleconnection and the anomalous Walker circulation (e.g., Nobre and Shukla 1996; Saravanan and Chang 2000; Chiang et al. 2002), with the trade wind anomalies being the critical means. Previous studies generally emphasized the first means being available during boreal winter and spring (e.g., Curtis and Hastenrath 1995; Nobre and Shukla 1996).

\subsection{Spatial structure of SST modulation}

The modulations of various SST modes on the Atlantic ITCZ and the basin-mean rainfall 
during boreal summer are further examined in this subsection. Table 1 shows the correlations between two rainfall indices $\left(\mathrm{P}_{\mathrm{ITCZ}}\right.$ and $\left.\mathrm{P}_{\mathrm{dm}}\right)$ and SST indices during JJA. The ENSO events can effectively impact rainfall variability in the tropical Atlantic as shown in Fig. 3 and past studies (e.g., Nobre and Shukla 1996; Enfield and Mayer 1997; Saravanan and Chang 2000; Chiang et al. 2002; Giannini et al. 2004). Particularly, a higher correlation is seen between Nino3.4 and $\mathrm{P}_{\mathrm{dm}}$, implying a wide-spread impact in the equatorial region. Similar correlation relationships can also be seen during MAM (Table 2).

Even higher correlations can be obtained between Atl3 and both $\mathrm{P}_{\text {ITCZ }}$ and $\mathrm{P}_{\mathrm{dm}}$ during JJA and MAM (Tables 1, 2). This suggests that although the Atlantic equatorial warm/cold events are relatively weak and even the major rainfall zone (the ITCZ) tends to be located about eight degrees north of the equator during boreal summer, the Atlantic equatorial mode can be one of the major factors controlling the ITCZ strength and the basin-mean rainfall.

For the impact of TNA and TNA1, large seasonal differences exist in their correlations with two rainfall indices $\left(\mathrm{P}_{\mathrm{ITCZ}}\right.$ and $\mathrm{P}_{\mathrm{dm}}$; Tables 1,2$)$. During JJA, $\mathrm{P}_{\text {ITCZ }}$ are significantly correlated with TNA and TNA1. The correlation between $\mathrm{P}_{\mathrm{dm}}$ and TNA1 is also significant, though relatively weaker. During MAM, however neither one is correlated to $\mathrm{P}_{\mathrm{ITCZ}}$ or $\mathrm{P}_{\mathrm{dm}}$. It is interesting to note that the correlation coefficients even have different signs during these two seasons.

The strength of the ITCZ and the domain-mean rainfall anomalies are affected by all these three SST indices, particularly during JJA. Also the ENSO has strong influences on Atl3 during both seasons, and on TNA during MAM (Table 3), it is thus interesting to estimate their individual impact by discriminating their influences from each other. Partial correlations are hence estimated between rainfall indices $\left(\mathrm{P}_{\mathrm{ITCZ}}\right.$ and $\left.\mathrm{P}_{\mathrm{dm}}\right)$ and one SST index with two other ones 
fixed during JJA and MAM (Tables 4, 5). Here, we assume the correlation relationships among these variables are linear and discernible. Without Atl3 and TNA, the ENSO impact becomes much weaker. There is even no significant correlation during MAM. This tends to suggest that the ENSO impact on rainfall anomalies in the tropical Atlantic may primarily go through its effect on the local SST modes, especially during MAM. During JJA, the impact becomes weaker too. However, the correlation between Nino3.4 and $\mathrm{P}_{\mathrm{dm}}$ is still statistically significant even with Atl3 and TNA not involved, suggesting the direct modulation likely through anomalous Walker circulations.

For Atl3, without the impact of Nino3.4 and TNA, its effect on rainfall become weaker, but the correlation coefficients are still well above the confidence level during both seasons. Given a weak relationship between Atl3 and TNA (Table 3), this correlation change is primarily due to the impact of the Pacific ENSO. TNA is strongly correlated to $\mathrm{P}_{\mathrm{ITCZ}}$ and $\mathrm{P}_{\mathrm{dm}}$ during JJA with the impact of Nino3.4 and Atl3 removed (Table 4) consistent with the view that ENSO and TNA have different effects. The larger impact of TNA on rainfall anomalies during JJA seems to be reasonable because the maritime ITCZ is then directly over the tropical north Atlantic (Fig. 1). The comparable partial correlation coefficients between $P_{\text {ITCZ, and Atl3 and TNA tend to }}$ provide a more feasible explanation than shown in Table 1. During MAM, the effect of TNA on rainfall is still negligible even without Nino3.4 and Atl3 involved (Table 5).

Although composite/regression maps have widely been used to show the spatial structure and evolution of tropical Atlantic variability (e.g., Ruiz-Barradas et al. 2000; Sutton et al. 2000; Wang 2002), only a few studies have primarily concentrated on rainfall variability and on the boreal summer season (e.g., Chiang et al. 2002; Gu and Adler 2006). Because of that, the rainfall and associated variability during boreal summer are focused on here. Regression maps are built 
based on three seasonal mean SST indices: At13, TNA, and Nino3.4, which are normalized by their corresponding standard deviations. As stated above, regression maps during MAM are also made for comparison. Partial correlations between these three SST indices and rainfall indices in Tables 4, 5 do show different magnitudes from the ones in Tables 1, 2, but do not change the signs of correlation except for TNA during MAM. Thus the regression maps based on three SST indices can provide a reasonable spatial description of related changes.

\subsubsection{Local influence}

Fig. 9 depicts the SST, surface wind, and precipitation anomalies associated with Atl3. During JJA, the spatial patterns generally agree with that shown in previous studies that primarily focused on the peak months of the Atlantic equatorial mode (e.g., Ruiz-Barradas et al. 2000; Wang 2002). Basin-wide warming is seen with the maximum SSTs along the equator with a tendency toward the eastern basin (Fig. 9b). Surface wind anomalies in general converge into the maximum, positive SST anomaly zone. Accompanying strong cross-equatorial flows being in the eastern equatorial region, anomalous westerlies are seen in the western basin extending from the equator to about $15^{\circ} \mathrm{N}$. These wind anomalies are related to the equatorial warming (Figs. 5, 6), and also might be the major reason for the warming-up in the TNA/TNA1 region. Positive rainfall anomalies are dominant in the entire basin, corresponding to warm SSTs. It is interesting to note that these rainfall anomalies tend to be over the same area as the seasonal mean rainfall variances (Fig. 1d). Particularly, over the open ocean the maximum rainfall anomaly band is sandwiched by the maritime ITCZ and the equatorial zone with maximum SST variability (Figs. 1c, 9b, 9d), confirming the strong modulations of the equatorial mode during this season (Fig. 2). During MAM, positive SST anomalies already appear along the equator (Fig. 9a). However, in 
addition to the SST anomalies along the equator, the most intense SST variability occurs right off the west coast of Central Africa, manifesting the frequent appearance of the Benguela Niño usually peaking in March-April (e.g., Florenchie et al. 2004). North of the equator, negative SST anomalies, though very weak, can be seen off the West African coast. This seems to suggest that the Atlantic Niño may effectively contribute to the interhemispheric SST mode, particularly to its southern lobe (Figs. 1b, 9a). Negative-positive rainfall anomalies across the equator forming a dipolar structure are evident, specifically west of $20^{\circ} \mathrm{W}$ (Fig. 9c). In the Gulf of Guinea, positive rainfall anomalies, though much weaker than in the western basin, can still be observed extending from the open ocean to the west coast of Central Africa, approximately following strong positive SST anomalies.

The SST, surface wind, and rainfall anomalies associated with TNA are shown in Fig. 10. Positive SST anomalies appear north of the equator during MAM, but become weaker during JJA. Surface vector wind anomalies converge into the warm SST region, resulting in decrease in the mean trade winds north of the equator. Cross-equatorial flow is strong during MAM, implying the TNA's contribution to the interhemispheric SST mode. On the other hand, no evident SST anomalies appear along and south of the equator supporting the view that the two lobes of the interhemispheric mode are not correlated (e.g., Enfield et al. 1999). A negativepositive rainfall dipolar feature occurs during MAM with much weaker anomalies east of $20^{\circ} \mathrm{W}$, consistent with previous studies (e.g., Nobre and Shukla 1996; Ruiz-Barradas et al. 2000; Chiang et al. 2002). During JJA, however only a single band of positive rainfall anomalies appears between $5^{\circ} \mathrm{N}-20^{\circ} \mathrm{N}$, covering the northern portion of the mean rainfall within the ITCZ and its variances (Figs. 1c, 1d, 10d). Interestingly this band tilts from southeast to northwest, tending to follow the tracks of tropical storms during the summer season. This might indicate the impact of 
TNA on the Atlantic hurricane activity (e.g., Xie et al. 2005).

\subsubsection{ENSO impact}

Fig. 11 shows the SST, surface wind, and rainfall anomalies regressed onto the seasonal mean Nino3.4. During MAM, positive-negative SST anomalies occur in the tropical region, shaping a dipolar structure accompanied by strong cross-equatorial surface flows. Compared to Figs. 9a and 10a, it is likely that ENSO may contribute to both lobes of the interhemispheric SST mode during this season (e.g., Chiang et al. 2002). Rainfall anomalies tend to be in the western basin and manifest as dipolar too. Compared with Figs. 9a and 9c, it is noticeable that along and south of the equator, ENSO shows a very similar impact feature as the Atlantic equatorial mode except with an opposite sign. This tends to enhance our arguments about their relations (Figs. 5, 6). During JJA, SST anomalies almost disappear north of the equator. South of the equator, negative SST anomalies can still be seen but weaker, accompanied by much weaker equatorial wind anomalies. Rainfall anomalies move to the north, as does the ITCZ. The dipolar feature can hardly be discernible. Again, rainfall anomalies show a very similar pattern as those related to At13 (Figs. 9d, 11d), though their signs are opposite. This suggests that during JJA the impact of ENSO on the tropical Atlantic may go through both its influence on the Atlantic equatorial mode and anomalous Walker cell (Table 4).

The correlations between SST anomalies and Nino3.4 during MAM and JJA are also estimated (Fig. 12). Significant correlation can be found both north and south of the equator during MAM with opposite signs, enhancing the regression analyses in Fig. 11a. During JJA, however there is no evident correlation zone north of about $5^{\circ} \mathrm{N}$ except near the northeast coast of South America where negative correlations occur. South of about $5^{\circ} \mathrm{N}$, a large area of negative 
correlation can be observed above the 5\% confidence level. The contrasts between MAM and JJA are closely related to the seasonal changes in the large-scale flow pattern that control the meridional propagation planetary waves (e.g., Webster and Holton 1982; Tomas and Webster 1994). This is central to the PNA mechanism (e.g., Horel and Wallace 1981). During MAM, upper-level mean flow becomes westerly (Fig. 13a), favorable for the equatorward-propagating of planetary waves (e.g., Webster and Holton 1982; Tomas and Webster 1994). However, easterly winds become dominant during JJA (Fig. 13b), so that the impact from the midlatitudes becomes impossible. On the other hand, the impact from the equatorial Pacific is still felt mostly along and south of the equator, particularly in the eastern basin, resulting from the anomalous Walker circulation and likely a lagged oceanic response to the wind and convective anomalies in the western basin during the preceding months (Figs. 4, 6).

\section{Summary and conclusions}

Rainfall anomalies and associated climate variability in the tropical Atlantic during boreal summer are investigated, and further compared with during boreal spring in which the most intense interannual variability is usually observed (e.g., Hastenrath and Greischar 1993; Nobre and Shukla 1996). Seasonal-mean rainfall during boreal summer shows intense interannual variabilities comparable with during boreal spring calibrated by both the ITCZ strength and the basin-mean rainfall. The latitudinal locations of the maritime ITCZ representing the major mean convective zone over the open ocean however do not vary much during boreal summer, in contrasting to evident fluctuations during boreal spring. Hence the summer-time rainfall variability is mostly manifested as the variations in the ITCZ strength and the basin-mean rainfall. 
Summer-time rainfall changes are further examined by means of analyzing their relationships with the two local SST modes and ENSO. The Atlantic Niño mode can effectively induce rainfall anomalies during boreal summer through accompanying anomalous surface winds and SST. These related rainfall anomalies are generally located over the major area of rainfall variance. TNA can contribute to the rainfall changes too during this season, but its impact is mostly limited to the northern portion of the ITCZ. The ENSO teleconnection mechanism may still play a role during boreal summer, although it becomes much weaker than during boreal spring. It is noted that the ENSO-associated spatial patterns tend to be similar to those related to the Atlantic Niño though with an opposite sign. This suggests that the impact of ENSO during boreal summer at least partly goes through its influence on the Atlantic Niño mode.

During boreal spring, TNA shows an evident impact on rainfall changes specifically in the region near and over the northeastern South America. The regression patterns are generally consistent with those using the index representing the interhemispheric SST mode (e.g., RuizBarradas et al. 2000), though the TNA-associated SST anomalies are weak and mostly north of the equator. This suggests a strong contribution of TNA to this interhemispheric mode and furthermore its independence of the SST oscillations south of the equator (e.g., Enfield et al. 1999). Atl3 and Nino3.4 can contribute to the interhemispheric SST mode too, in addition to their direct modulations of rainfall change in the basin. Particularly in the western basin (west of $20^{\circ} \mathrm{W}$ ), corresponding to evident oscillations of the ITCZ latitudes during MAM, a dipolar feature of rainfall anomalies occurs in the regression maps for both indices. Simultaneously strong surface wind anomalies appear with evident cross-equatorial components.

To further explore the relationships among the two local SST modes and ENSO, contemporaneous and lag correlations are estimated among various parameters. ENSO shows 
strong impact on the Atlantic equatorial region and the tropical north Atlantic. Significant, simultaneous correlations between Nino3.4 and TNA are seen during February-April. Significant lag-correlations of TNA at its peak month (April) with Nino3.4 one or several months earlier further confirm that the impact from the tropical Pacific is a major contributor during boreal spring (e.g., Chiang et al. 2000). Nino3.4 is highly correlated with Atl3 during April-June. The correlations between Nino3.4 and the zonal wind index in the western basin $\left(U_{\text {Watl }}\right)$ become high during February-July except in March. Moreover the maximum correlation between $U_{\text {Watl }}$ in May (peak month) and Nino3.4 is seen as Nino3.4 precedes it by one month, indicating the remote modulations of wind anomalies. The Pacific ENSO can effectively modulate convection and surface winds during boreal spring through two ways: the PNA and the anomalous Walker cell (e.g., Nobre and Shukla 1996; Chiang and Sobel 2002). Trade wind anomalies are a pathway for the SST oscillations north of the equator (e. g., Curtis and Hastenrath 1995; Enfield and Mayer 1997). Along and south of the equator, convective and wind anomalies in the western basin are the critical means for the ENSO impact. During boreal summer, the pathway from the midlatitudes becomes impossible due to seasonal changes in the large-scale mean flows, and the ITCZ moves away from the equator. Hence, the ENSO impact on the tropical region is greatly limited. The lag-correlations between Atl3 at the peak month (June) and Nino3.4 and U Uatl, respectively, tend to suggest that the equatorial oscillation is excited by the preceding zonal wind anomalies in the western basin which are closely related to the ENSO. The lag and simultaneous correlations of Atl3 with $U_{\text {Watl }}$ further imply that it is a coupled mode to a certain extent. It is interesting to further note that high positive correlations can be found between Atl3 and TNA/TNA1 during July-October. This implies that during boreal summer the Atlantic equatorial mode may have a much more comprehensive impact, in addition to its influence on the ITCZ, 
than expected.

In summary, the Atlantic Niño and Pacific ENSO are two major modulators of rainfall anomalies in the equatorial Atlantic during JJA, in addition to the contribution from the SST anomalies in the tropical north Atlantic. However the impact of the Pacific ENSO may work through both its effect on the Atlantic equatorial mode and on the regional Walker cell.

\section{Acknowledgements}

Mr. David Bolvin prepared the GPCP monthly precipitation data. The NCAR/DOE AMIP-II Reanalysis data and the NCEP SST product were provided by the NOAA-CIRES Climate Diagnostics Center, Boulder, Colorado, USA, from its Web site at http://www.cdc.noaa.gov. This study was supported by NOAA's Office of Global Programs under grant NA05QAR4311133 and by NASA?'s Precipitation Mission. 


\section{References}

Adler, R. F., and Coauthors, 2003: The version 2 Global Precipitation Climatology Project (GPCP) monthly precipitation analysis (1979-present). J. Hydrometeor, 4, 1147-1167.

Biasutti, M., D.S. Battisti, and E.S. Sarachik, 2004: Mechanisms controlling the annual cycle of precipitation in the tropical Atlantic sector in an atmospheric GCM. J. Climate, 17, 47084723.

Carton, J. A., and B. Huang, 1994: Warm events in the tropical Atlantic. J. Phys. Oceanogr., 24, $888-903$.

Chen, Y. L., and Y. Ogura, 1982: Modulation of convective activity by large-scale flow patterns observed in GATE. J. Atmos. Sci., 39, 1260-1279.

Chiang, J. C. H., Y. Kushnir, and S. E. Zebiak, 2000: Interdecadal changes in eastern Pacific ITCZ variability and its influence on the Atlantic ITCZ. Geophys. Res. Lett., 27, 3687-3690.

Chiang, J. C. H., Y. Kushnir, and A. Hiannini, 2002: Reconstructing Atlantic Intertropical Convergence Zone variability: Influence of the local cross-equatorial sea surface temperature gradient and remote forcing from the eastern equatorial Pacific. J. Geophys. Res., 107(D1), 4004, doi:10.1029/2000JD000307.

Chiang, J.C.H., A.H. Sobel, 2002: Tropical tropospheric temperature variations caused by ENSO and their influence on the remote tropical climate. J. Climate, 15, 2616-2631.

Curtis, S., and S. Hastenrath, 1995: Forcing of anomalous sea surface temperature evolution in the tropical Atlantic during Pacific warm events. J. Geophys. Res., 100, 15835-15847.

Czaja, A., 2004: Why is North Tropical Atlantic SST variability stronger in boreal spring? J. Climate, 17, 3017-3025.

Delecluse, P., J. Servain, C. Levy, K. Arpe, and L. Bengtsson, 1994: On the connection between 
the 1984 Atlantic warm event and the 1982-1983 ENSO. Tellus, 46A, 448-464.

Enfield, D. B., and D. A. Mayer, 1997: Tropical Atlantic sea surface temperature variability and its relation to El Niño-Southern Oscillation. J. Geophys. Res., 102, 929-945

Enfield, D. B., A. M. Mestas-Nunez, D. A. Mayer, and L. Cid-Serrano, 1999: How ubiquitous is the dipole relationship in tropical Atlantic sea surface temperature? J. Geophys. Res., 104, 7841-7848.

Florenchie, P., C.J.C. Reason, J.R.E. Lutjeharms, M. Rouault, C. Roy, and S. Masson, 2004: Evolution of interannual warm and cold events in the southeast Atlantic Ocean. J. Climate, $17,2318-2334$.

Giannini, A., R. Saravanan, and P. Chang, 2004: The preconditioning role of Tropical Atlantic Variability in the development of the ENSO teleconnection: Implication for the predictability of Nordeste rainfall. Climate Dyn., 22, 839-855.

Gill, A. E., 1982: Atmosphere-Ocean Dynamics. Academic Press, 662pp.

Gu, G., and R. F. Adler, 2004: Seasonal Evolution and Variability Associated with the West African Monsoon System. J. Climate, 17, 3364-3377.

Gu, G., and R. F. Adler, 2006: Interannual rainfall variability in the tropical Atlantic region. $J$. Geophys. Res., 111, D02106, doi:10.1029/2005JD005944.

Gu, G., and C. Zhang, 2001: A spectrum analysis of synoptic-scale disturbances in the ITCZ. J. Climate, 14, 2725-2739.

Hastenrath, S., and L. Greischar, 1993: Circulation mechanisms related to northeast Brazil rainfall anomalies. J. Geophys. Res., 98, 5093-5102.

Horel, J.D., and J.M. Wallace, 1981: Planetary-scale atmospheric phenomena associated with the southern oscillation. Mon. Wea. Rev., 109, 813-829. 
Kanamitsu, M., W. Ebisuzaki, J. Woollen, S.-K. Yang, J.J. Hnilo, M. Fiorino, and G.L. Potter, 2002: NCEP-DOE AMIP-II Reanalysis (R-2). Bull. Amer. Meteor. Soc., 83, 1631-1643.

Lamb, P.J., 1978a: Large scale tropical Atlantic surface circulation patterns during recent subSaharan weather anomalies. Tellus, 30, 240-251.

Lamb, P.J., 1978b: Case studies of tropical Atlantic surface circulation patterns during recent sub-Saharan weather anomalies: 1967 and 1978. Mon. Wea. Rev., 106, 482-491.

Landsea, C.W., R.A. Pielke Jr., A.M. Mesta-Nunez, and J.A. Knaff, 1999: Atlantic basin hurricanes: Indices of climate changes. Climate Change, 42, 89-129.

Latif, M., and A. Grötzner, 2000: The equatorial Atlantic oscillation and its response to ENSO. Climate Dyn., 16, 213-218.

Mitchell, T.P., and J.M. Wallace, 1992: The annual cycle in equatorial convection and sea surface temperature. J. Climate, 5, 1140-1156.

Münnich, M., and J. D. Neelin, 2005: Seasonal influence of ENSO on the Atlantic ITCZ and equatorial South America. Geophys. Res. Lett., 32, L21709, doi:10.1029/2005GL023900.

Nobre, P., and J. Shukla, 1996: Variations of sea surface temperature, wind stress, and rainfall over the tropical Atlantic and South America. J. Climate, 9, 2464-2479.

Reynolds, R. W., N. A. Rayner, T. M. Smith, D. C. Stokes and W. Wang, 2002: An improved in situ and satellite SST analysis for climate. J. Climate, 15, 1609-1625.

Ruiz-Barradas, A., J. A. Carton, and S. Nigam, 2000: Structure of interannual-to-decadal climate variability in the tropical Atlantic sector. J. Climate, 13, 3285-3297.

Saravanan, R., and P. Chang, 2000: Interaction between tropical Atlantic variability and El NiñoSouthern oscillation. J. Climate, 13, 2177-2194.

Sutton, R. T., S. P. Jewson, and D. P. Rowell, 2000: The elements of climate variability in the 
tropical Atlantic region. J. Climate, 13, 3261-3284.

Thorncroft, C. D., and D. P. Rowell, 1998: Interannual variability of African wave activity in a general circulation model. Int. J. Climatol., 18, 1306-1323.

Tomas, R.A., and P.J. Webster, 1994: Horizontal and vertical structure of cross-equatorial wave propagation. Q. J. R. Meteorol. Soc., 51, 1417-1430.

Wagner, R. G., 1996: Decadal-scale trends in mechanisms controlling meridional sea surface temperature gradients in the tropical Atlantic. J. Geophys. Res., 101, 16683-16694.

Wang, C., 2002: Atlantic climate variability and its associated atmospheric circulation cells. $J$. Climate, 15, 1516-1536.

Webster, P.J., and J.R. Holton, 1982: Cross-equatorial response to middle-latitude forcing in a zonally varying basic state. J. Atmos. Sci., 39, 722-733.

Xie, L., T. Yan, and L. Pietrafesa, 2005: The effect of Atlantic sea surface temperature dipole mode on hurricanes: Implications for the 2004 Atlantic hurricane season. Geophys. Res. Lett., 32, L03701, doi:10.1029/2004GL021702.

Zebiak, S. E., 1993: Air-sea interaction in the equatorial Atlantic region. J. Climate, 6, 15671586. 


\section{Table Legends:}

Table 1 Correlation coefficients $(\gamma)$ between $\mathrm{P}_{\mathrm{ITCZ}}$ and $\mathrm{P}_{\mathrm{dm}}\left(\mathrm{mm}\right.$ day $\left.{ }^{-1}\right)$ with various SST indices during JJA. $\gamma= \pm 0.40$ is the $5 \%$ confidence level based on 23 degrees of freedom (dof).

Table 2 Correlation coefficients $(\gamma)$ between $P_{\text {ITCZ }}$ and $P_{d m}\left(m m\right.$ day $\left.{ }^{-1}\right)$, and various SST indices during MAM. $\gamma= \pm 0.40$ is the $5 \%$ confidence level based on $(n-2=) 23$ degrees of freedom (dof).

Table 3 Correlation coefficients $(\gamma)$ among three SST indices during MAM and JJA. $\gamma= \pm 0.40$ is the $5 \%$ confidence level based on $(n-2=) 23$ degrees of freedom (dof).

Table 4 Partial correlation coefficients $(\gamma)$ between $P_{\text {ITCZ }}$ and $P_{d m}\left(m m\right.$ day $\left.{ }^{-1}\right)$, and one SST index with two other SST indices fixed during JJA. $\gamma= \pm 0.41$ is the $5 \%$ confidence level based on $(\mathrm{n}-4=) 21$ degrees of freedom (dof).

Table 5 Partial correlation coefficients $(\gamma)$ between $P_{\text {ITCZ }}$ and $P_{d m}\left(\mathrm{~mm}^{-1 a y}{ }^{-1}\right)$, and one SST index with two other SST indices fixed during MAM. $\gamma= \pm 0.41$ is the $5 \%$ confidence level based on $(n-4=) 21$ degrees of freedom (dof). 


\section{Figure Captions:}

Figure 1 Seasonal mean rainfall ( $\mathrm{mm}$ day ${ }^{-1}$; contours) and SST $\left({ }^{\circ} \mathrm{C}\right.$; color shades) during (a) March-May (MAM) and (c) June-August (JJA); Seasonal mean variances of rainfall (mm² day $^{-2}$; contours) and SST $\left[\left({ }^{\circ} \mathrm{C}\right)^{2}\right.$; color shades $]$ during (b) MAM and (d) JJA.

Figure 2 Time series of (a) the domain-mean rainfall $\left(\mathrm{P}_{\mathrm{dm}}\right),(\mathrm{b})$ the ITCZ strength $\left(\mathrm{P}_{\text {ITCZ }}\right)$, and (c) the ITCZ latitudes (Lat ${ }_{\text {ITCZ }}$ ) during MAM (dash-dot lines) and JJA (solid lines).

Figure 3 Correlation maps of SST anomalies with the ITCZ strength ( $\mathrm{P}_{\text {ITCZ }}$ ) during (a) MAM and (b) JJA. The $5 \%$ confidence level is \pm 0.40 based on 23 degrees of freedom (dof).

Figure 4 Variances of various indices as function of month. Variance of Nino 3.4 is scaled by 2.

Figure 5 Correlation coefficients between various indices as function of month. The $5 \%$ confidence level is \pm 0.40 based on 23 dofs.

Figure 6 Lag-correlations between At13 in June with Nino3.4 (solid line) and UWAtl (dashed line), respectively. Positive (negative) months indicate Atl3 leads (lags) Nino3.4 and U UAtl. The $5 \%$ confidence level is \pm 0.40 based on 22 dofs.

Figure 7 Lag-correlation between $U_{\text {WAtl }}$ in May with Nino3.4. Positive (negative) months indicate $\mathrm{U}_{\mathrm{WAtl}}$ leads (lags) Nino3.4. The $5 \%$ confidence level is \pm 0.40 based on 22 dofs.

Figure 8 Lag-correlations between TNA and TNA1 in April with Nino3.4. Positive (negative) months indicate TNA and TNA1 lead (lag) Nino3.4. The $5 \%$ confidence level is \pm 0.40 based on 22 dofs. 
Figure 9 Regression maps of SST and surface wind (a, b), and precipitation (c, d) anomalies against At13 during MAM (a, c) and JJA (b, d).

Figure 10 Regression maps of SST and surface wind (a, b), and precipitation (c, d) anomalies against TNA during MAM $(a, c)$ and JJA $(b, d)$.

Figure 11 Regression maps of SST and surface wind (a,b), and precipitation (c, d) anomalies against Nino3.4 during MAM (a, c) and JJA (b, d).

Figure 12 Correlation maps of SST anomalies with Nino3.4 during (a) MAM and (b) JJA. The $5 \%$ confidence level is \pm 0.40 based on 23 dofs.

Figure 13 Seasonal mean wind fields at $200 \mathrm{hPa}$ over the tropical Atlantic during (a) MAM and (b) JJA. Contours are for zonal wind component. 
Table 1 Correlation coefficients $(\gamma)$ between $P_{\text {ITCZ }}$ and $P_{d m}\left(\mathrm{~mm}_{\text {day }}{ }^{-1}\right)$, and various SST indices during JJA. $\gamma= \pm 0.40$ is the $5 \%$ confidence level based on $(n-2=) 23$ degrees of freedom (dof).

\begin{tabular}{|c|c|c|c|c|}
\hline$\gamma$ & Nino3.4 & Atl3 & TNA & TNA1 \\
\hline P $_{\text {ITCZ }}$ & $\mathbf{- 0 . 5 0}$ & $\mathbf{0 . 6 7}$ & $\mathbf{0 . 5 2}$ & $\mathbf{0 . 5 8}$ \\
\hline$P_{\mathrm{dm}}$ & $\mathbf{- 0 . 6 2}$ & $\mathbf{0 . 7 5}$ & 0.39 & $\mathbf{0 . 4 5}$ \\
\hline
\end{tabular}


Table 2 Correlation coefficients $(\gamma)$ between $\mathrm{P}_{\mathrm{ITCZ}}$ and $\mathrm{P}_{\mathrm{dm}}\left(\mathrm{mm}\right.$ day $\left.{ }^{-1}\right)$, and various SST indices during MAM. $\gamma= \pm 0.40$ is the $5 \%$ confidence level based on $(n-2=) 23$ degrees of freedom (dof).

\begin{tabular}{|c|c|c|c|c|}
\hline$\gamma$ & Nino3.4 & At13 & TNA & TNA1 \\
\hline $\mathrm{P}_{\mathrm{ITCZ}}$ & $\mathbf{- 0 . 5 0}$ & $\mathbf{0 . 5 7}$ & -0.18 & -0.21 \\
\hline $\mathrm{P}_{\mathrm{dm}}$ & $\mathbf{- 0 . 6 3}$ & $\mathbf{0 . 6 6}$ & -0.26 & -0.28 \\
\hline
\end{tabular}


Table 3 Correlation coefficients $(\gamma)$ among three SST indices during MAM and JJA. $\gamma= \pm 0.40$ is the $5 \%$ confidence level based on $(n-2=) 23$ degrees of freedom (dof).

\begin{tabular}{|c|c|c|c|}
\hline$\gamma$ & Nino3.4 vs Atl3 & Nino3.4 vs TNA & At13 vs TNA \\
\hline MAM & $\mathbf{- 0 . 5 3}$ & $\mathbf{0 . 5 2}$ & -0.16 \\
\hline JJA & $\mathbf{- 0 . 4 6}$ & -0.06 & 0.17 \\
\hline
\end{tabular}


Table 4 Partial correlation coefficients $(\gamma)$ between $\mathrm{P}_{\mathrm{ITCZ}}$ and $\mathrm{P}_{\mathrm{dm}}\left(\mathrm{mm}\right.$ day $\left.{ }^{-1}\right)$, and one SST index with two other SST indices fixed during JJA. $\gamma= \pm 0.41$ is the $5 \%$ confidence level based on (n-4=) 21 degrees of freedom (dof).

\begin{tabular}{|c|c|c|c|}
\hline$\gamma$ & Nino3.4 & At13\&TNA $_{\text {At13034\&TNA }}$ & TNA $_{\text {Nino34\&At13 }}$ \\
\hline $\mathrm{P}_{\text {ITCZ }}$ & -0.36 & $\mathbf{0 . 5 9}$ & $\mathbf{0 . 5 8}$ \\
\hline $\mathrm{P}_{\mathrm{dm}}$ & $\mathbf{- 0 . 5 2}$ & $\mathbf{0 . 6 7}$ & $\mathbf{0 . 4 7}$ \\
\hline
\end{tabular}


Table 5 Partial correlation coefficients $(\gamma)$ between $P_{\text {ITCZ }}$ and $P_{d m}\left(m m\right.$ day $\left.{ }^{-1}\right)$, and one SST index with two other SST indices fixed during MAM. $\gamma= \pm 0.41$ is the $5 \%$ confidence level based on (n4=) 21 degrees of freedom (dof).

\begin{tabular}{|c|c|c|c|}
\hline$\gamma$ & Nino3.4 $_{\text {Atl3\&TNA }}$ & Atl3 $_{\text {Nino34\&TNA }}$ & TNA $_{\text {Nino34\&At3 }}$ \\
\hline $\mathrm{P}_{\text {ITCZ }}$ & -0.27 & 0.40 & 0.05 \\
\hline $\mathrm{P}_{\mathrm{dm}}$ & -0.39 & $\mathbf{0 . 4 8}$ & 0.03 \\
\hline
\end{tabular}


Rainfall and SST

(a)

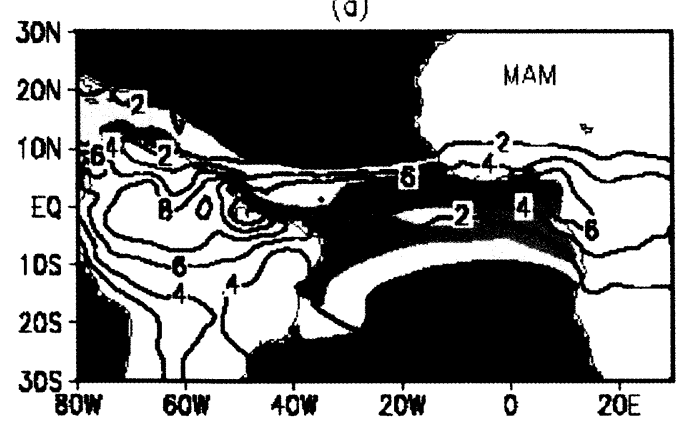

(c)

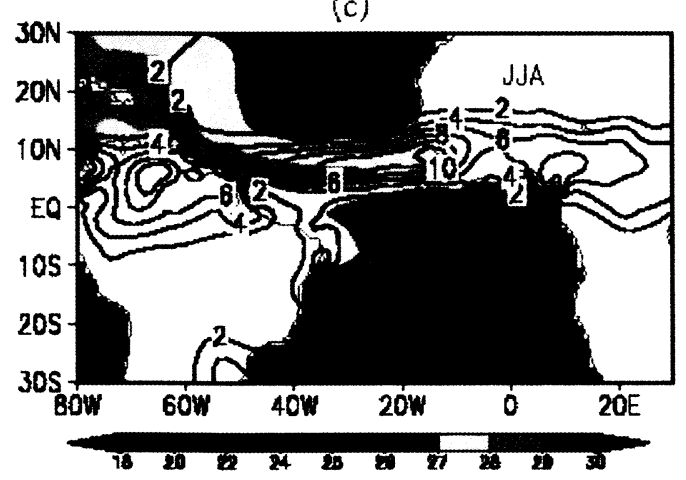

Rainfall and SST Varionce

(b)

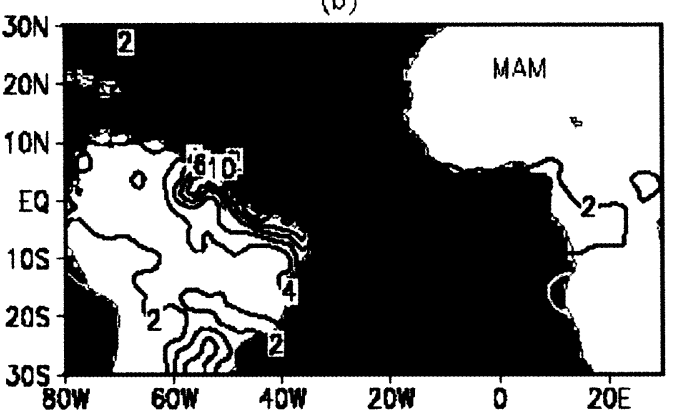

(d)

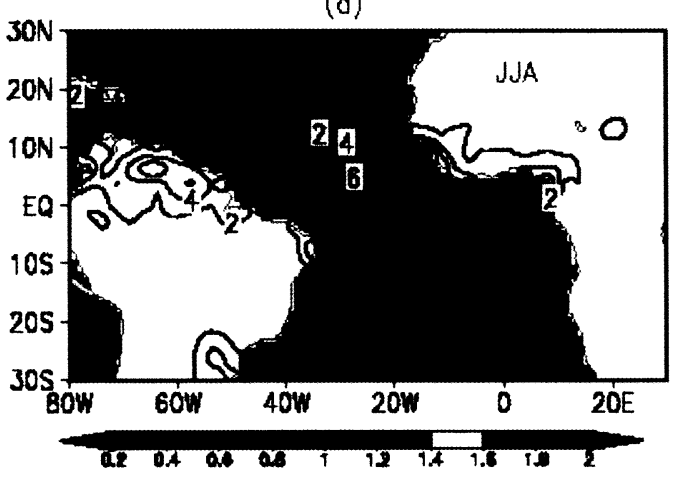

Figure 1 Seasonal mean rainfall (mm day ${ }^{-1}$; contours) and SST $\left({ }^{\circ} \mathrm{C}\right.$; color shades) during (a) March-May (MAM) and (c) June-August (JJA); Seasonal mean variances of rainfall ( $\mathrm{mm}^{2} \mathrm{day}^{-2}$; contours) and SST $\left[\left({ }^{\circ} \mathrm{C}\right)^{2}\right.$; color shades $]$ during (b) MAM and (d) JJA. 

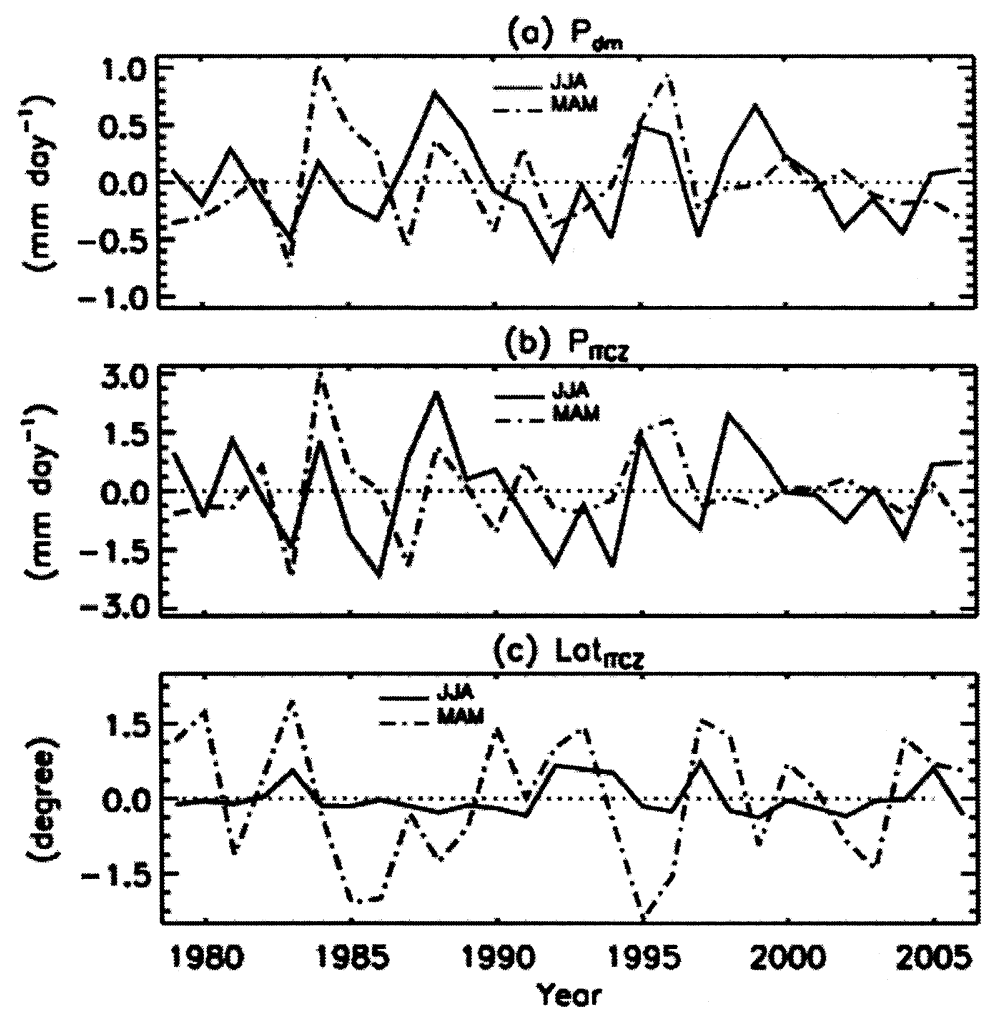

Figure 2 Time series of (a) the domain-mean rainfall $\left(\mathrm{P}_{\mathrm{dm}}\right)$, (b) the ITCZ strength $\left(\mathrm{P}_{\text {ITCZ }}\right)$, and (c) the ITCZ latitudes (Lat $\mathrm{ITCZ}_{\mathrm{T}}$ ) during MAM (dash-dot lines) and JJA (solid lines). 
(a) MAM

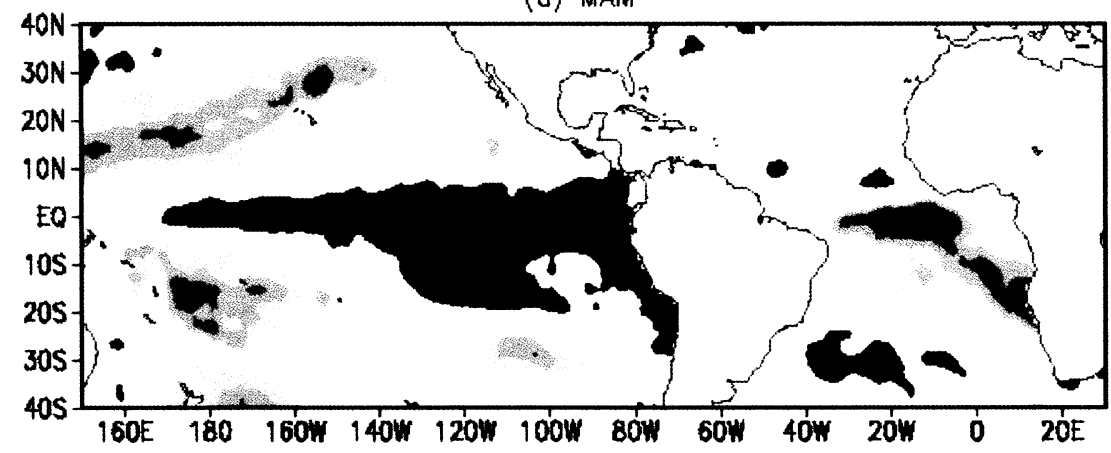

(b) JUA

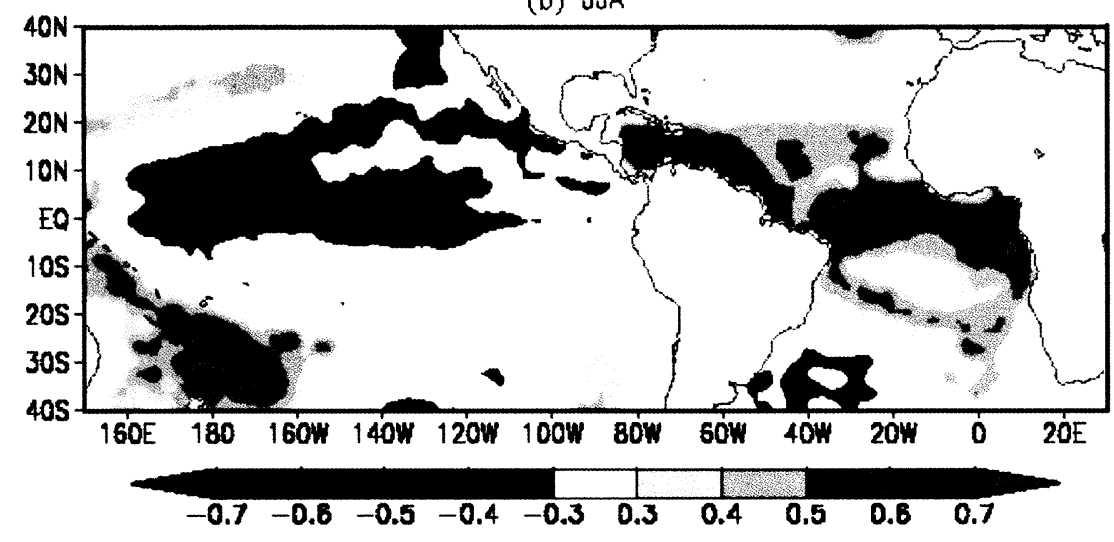

Figure 3 Correlation maps of SST anomalies with the ITCZ strength ( $\left.\mathrm{P}_{\text {ITCZ }}\right)$ during (a) MAM and (b) JJA. The $5 \%$ confidence level is \pm 0.40 based on 23 degrees of freedom (dof). 


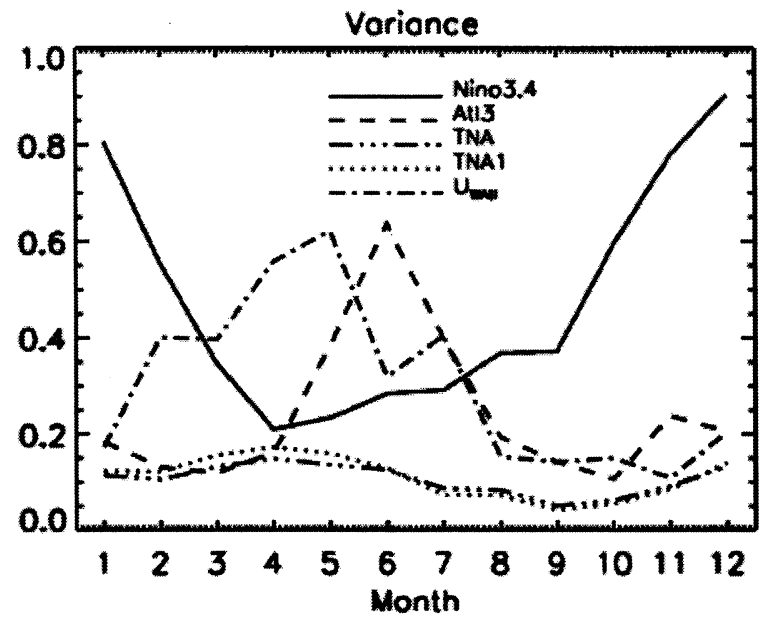

Figure 4 Variances of various indices as function of month. Variance of Nino 3.4 is scaled by 2 . 


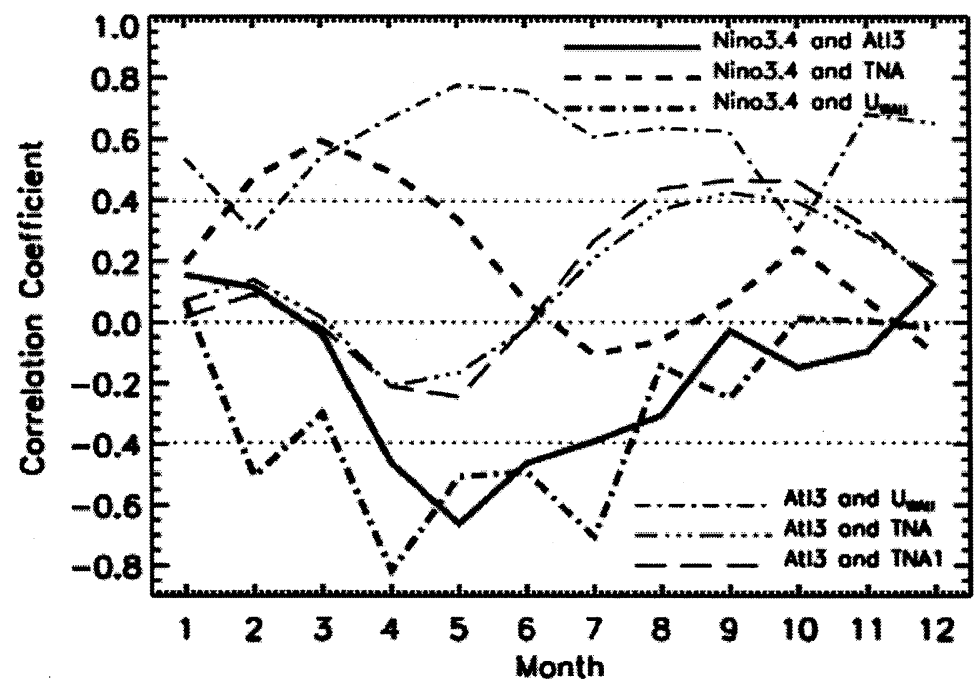

Figure 5 Correlation coefficients between various indices as function of month. The $5 \%$ confidence level is \pm 0.40 based on 23 dofs. 


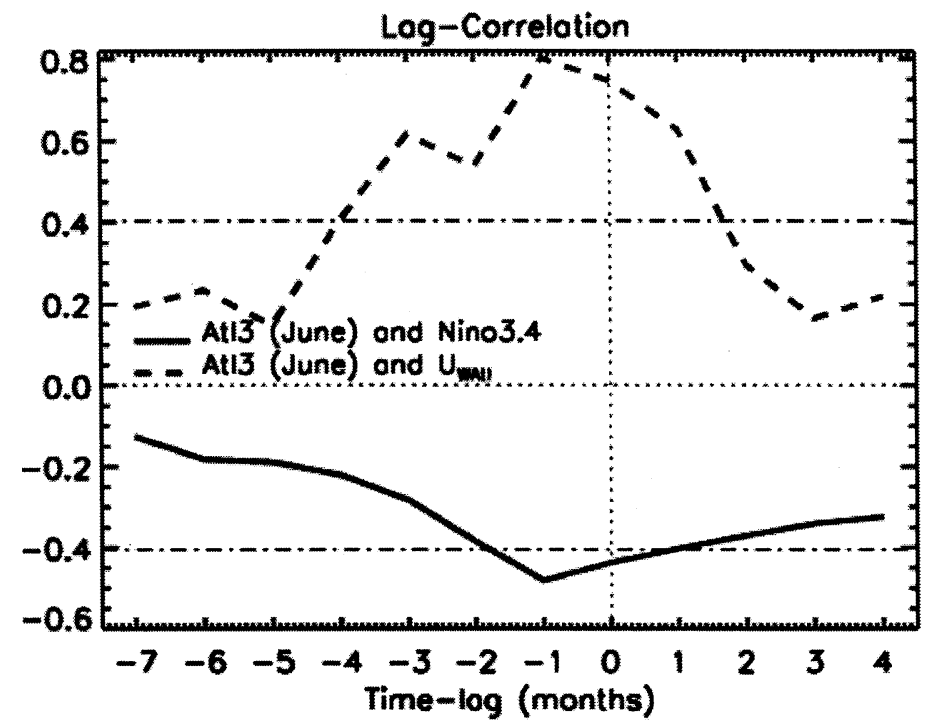

Figure 6 Lag-correlations between At13 in June with Nino3.4 (solid line) and $U_{\text {WAtl }}$ (dashed line), respectively. Positive (negative) months indicate Atl3 leads (lags) Nino3.4 and $\mathrm{U}_{\text {WAtl. }}$ The 5\% confidence level is \pm 0.40 based on 22 dofs. 


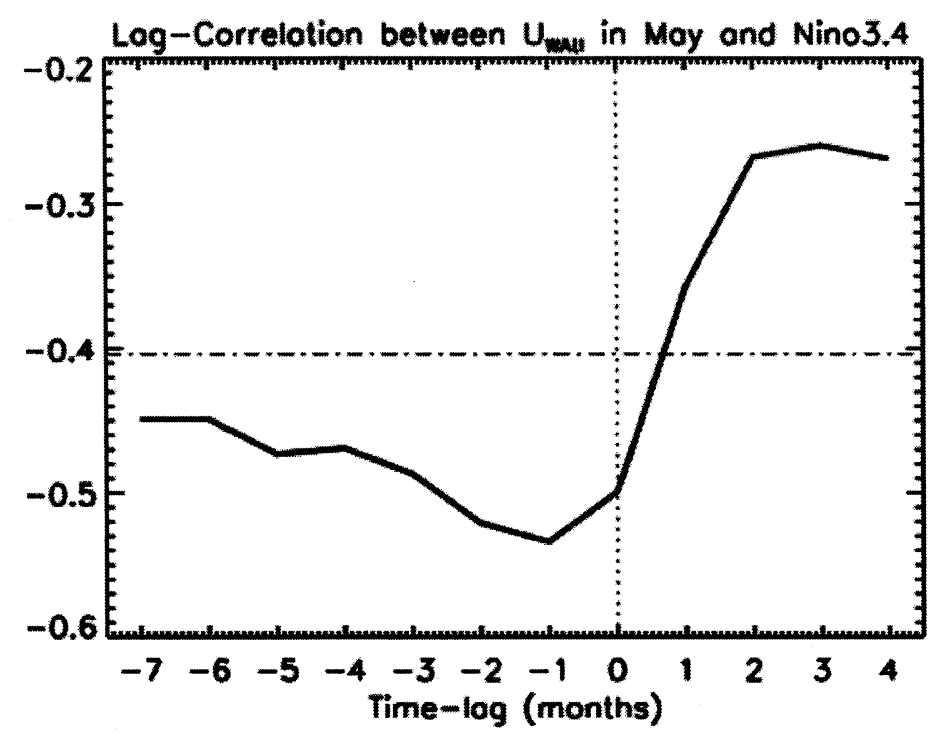

Figure 7 Lag-correlation between $U_{\text {WAtl }}$ in May with Nino3.4. Positive (negative) months indicate $U_{\mathrm{WAtl}}$ leads (lags) Nino3.4. The $5 \%$ confidence level is \pm 0.40 based on 22 dofs. 


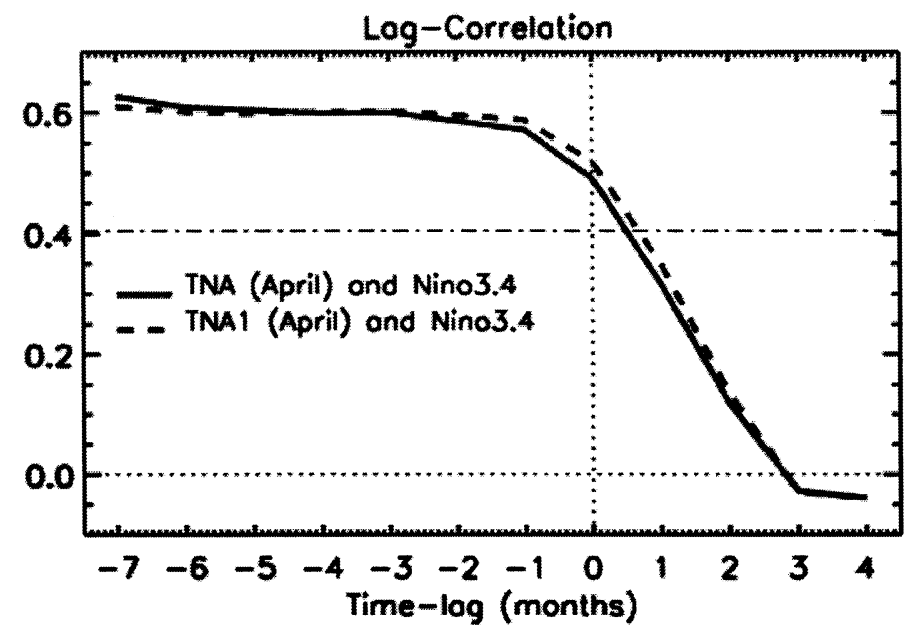

Figure 8 Lag-correlations between TNA and TNA1 in April with Nino3.4. Positive (negative) months indicate TNA and TNA1 lead (lag) Nino3.4. The $5 \%$ confidence level is \pm 0.40 based on 22 dofs. 

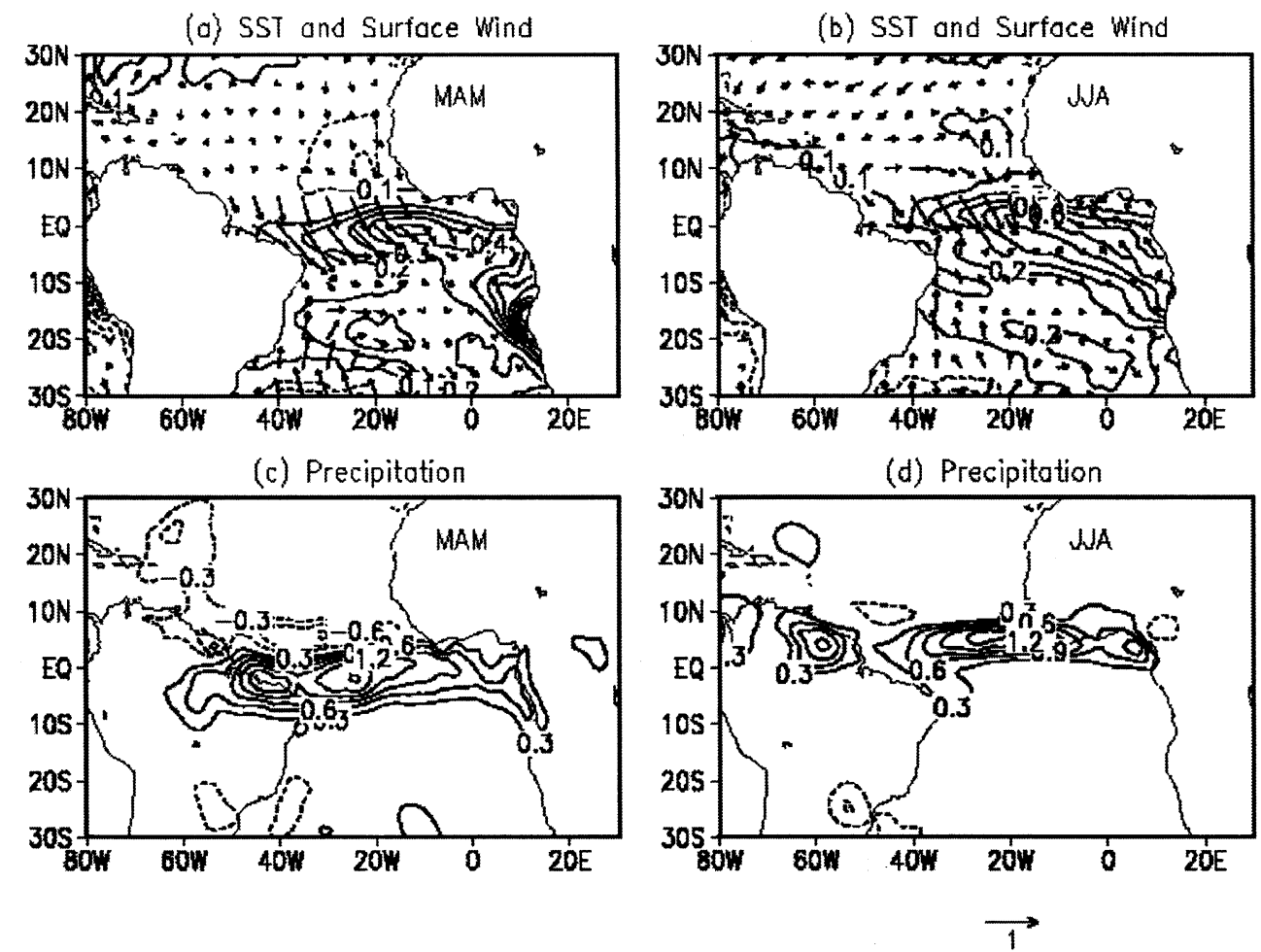

Figure 9 Regression maps of SST and surface wind (a, b), and precipitation (c, d) anomalies against Atl3 during MAM (a, c) and JJA (b, d). 
(a) SST and Surface Wind

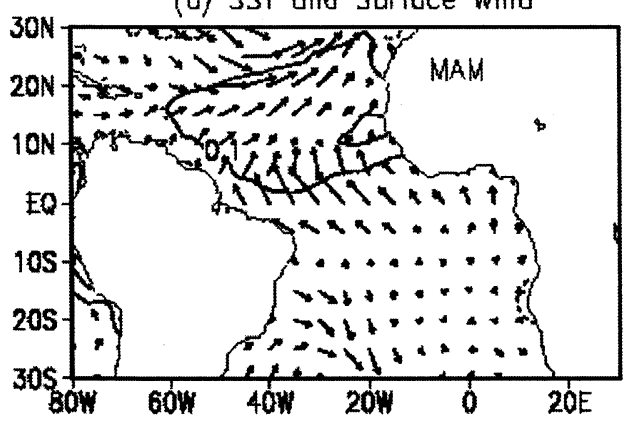

(c) Precipitation

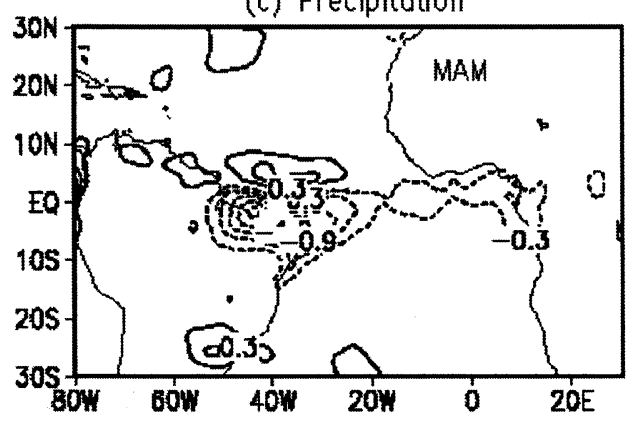

(b) SST and Surfoce Wind

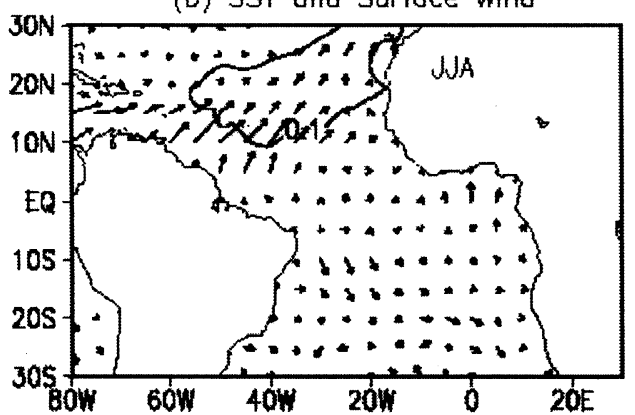

(d) Precipitation

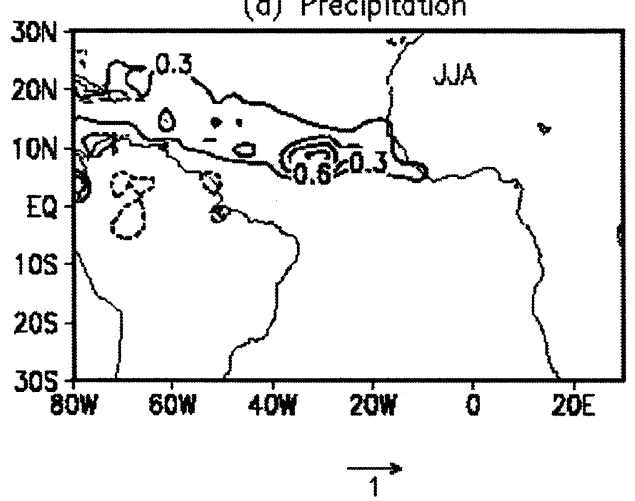

Figure 10 Regression maps of SST and surface wind (a, b), and precipitation (c, d) anomalies against TNA during MAM (a, c) and JJA (b, d). 
(a) SST and Surface Wind
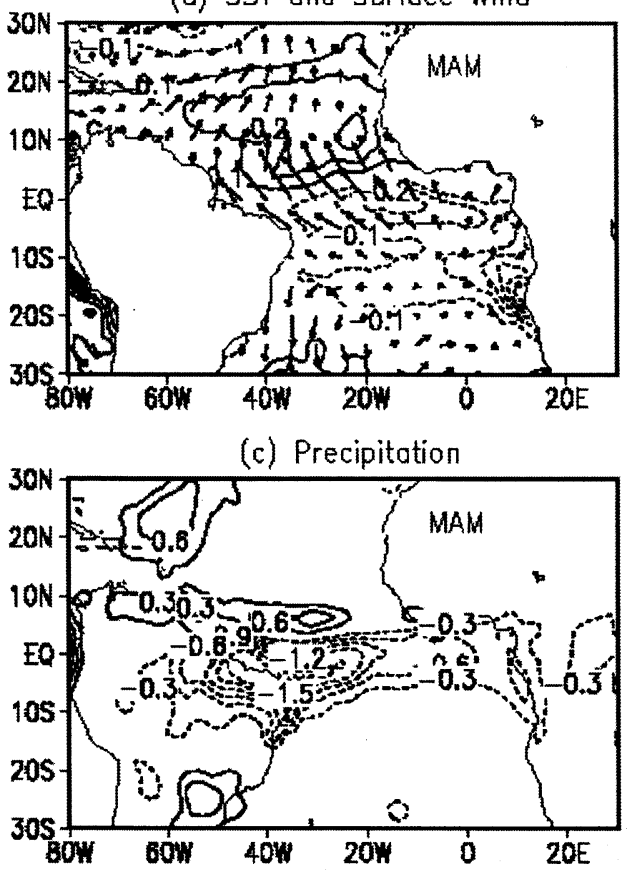

(b) SST and Surfoce Wind

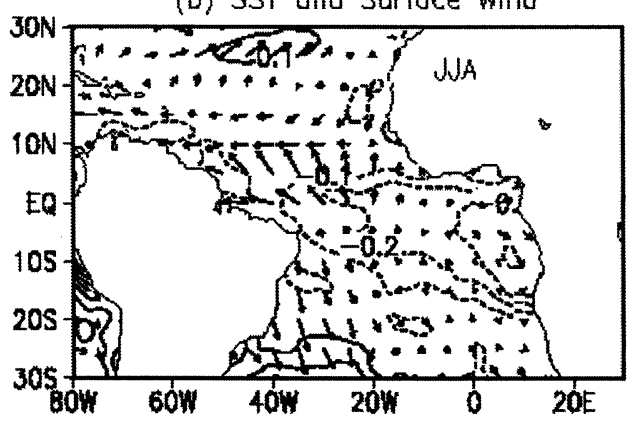

(d) Precipitation

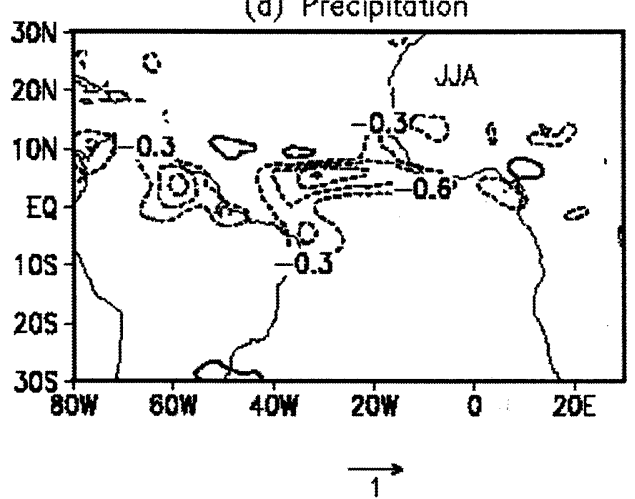

Figure 11 Regression maps of SST and surface wind (a, b), and precipitation (c, d) anomalies against Nino3.4 during MAM (a, c) and JJA (b, d). 

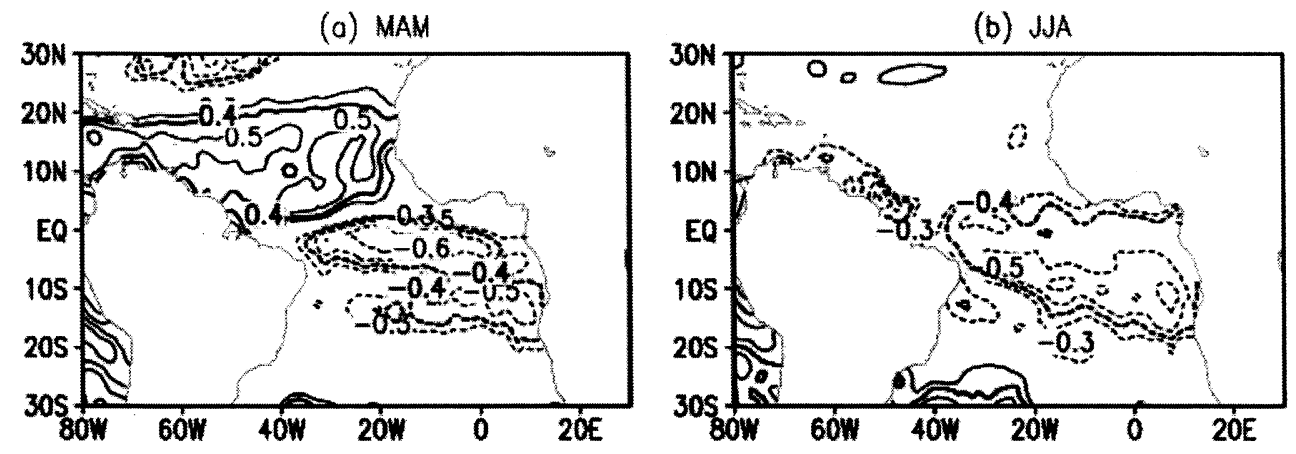

Figure 12 Correlation maps of SST anomalies with Nino3.4 during (a) MAM and (b) JJA. The $5 \%$ confidence level is \pm 0.40 based on 23 dofs. 
(o) MAM

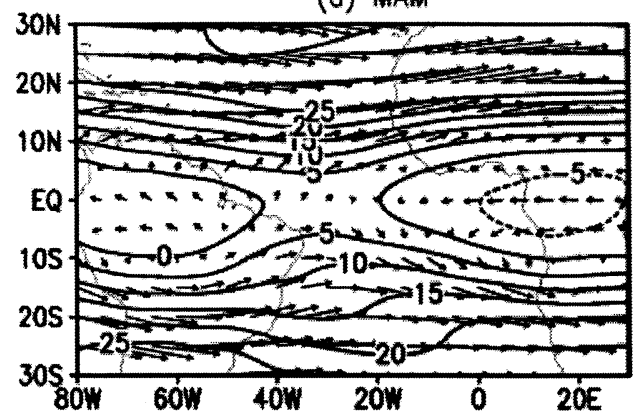

(b) JUA

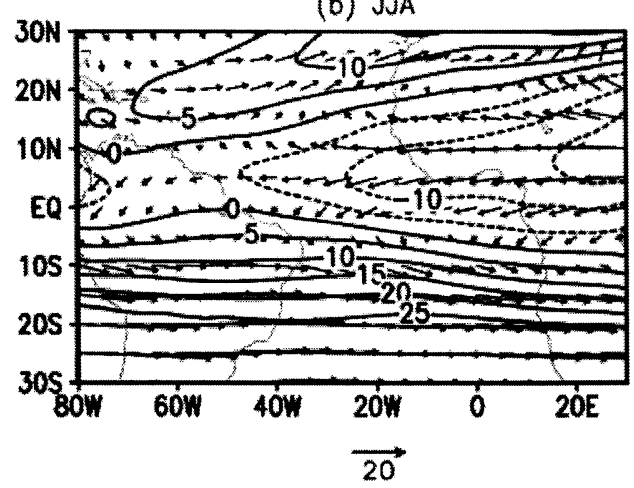

Figure 13 Seasonal mean wind fields at $200 \mathrm{hPa}$ over the tropical Atlantic during (a) MAM and (b) JJA. Contours are for zonal wind component. 